\title{
The molecular pathology of hereditary breast cancer: genetic testing and therapeutic implications
}

\author{
Emiliano Honrado ${ }^{1}$, Javier Benítez ${ }^{1}$ and José Palacios ${ }^{2}$ \\ ${ }^{1}$ Human Genetics Department, Centro Nacional de Investigaciones Oncológicas (CNIO), Madrid, Spain and \\ ${ }^{2}$ Breast and Gynaecological Cancer Group, Centro Nacional de Investigaciones Oncológicas (CNIO), Madrid, \\ Spain
}

\begin{abstract}
Cancer arising in carriers of mutations in the BRCA1 and BRCA2 genes differs from sporadic breast cancer of age-matched controls and from non-BRCA1/2 familial breast carcinomas in its morphological, immunophenotypic and molecular characteristics. Most BRCA1 carcinomas have the basal cell phenotype, a subtype of highgrade, highly proliferating, estrogen receptor- and HER2-negative breast carcinomas, characterized by the expression of basal or myoepithelial markers such as basal keratins, P-cadherin, epidermal growth factor receptor, etc. This phenotype is rarely found in BRCA2 carcinomas, which are of higher grade than sporadic age-matched controls, but tend to be estrogen receptor- and progesterone receptor-positive. The expression of the cell-cycle proteins cyclins A, B1 and E and SKP2 is associated with a BRCA1 phenotype, whereas cyclin D1 and p27 expression is associated with BRCA2 carcinomas. Recent studies have shown that hereditary carcinomas that are not attributable to $B R C A 1 / 2$ mutations have phenotypic similarities to $B R C A 2$ tumors, but tend to be of lower grade and proliferation index. Somatic mutations in the BRCA genes are rarely found in hereditary tumors; by contrast, BRCA1 and BRCA2 loss of heterozygosity (LOH) is found in almost all BRCA1 and BRCA2 carcinomas, respectively. Furthermore, all types of hereditary breast carcinomas have a low frequency of HER2 expression. Finally, comparative genomic hybridization studies have revealed differences in chromosomal gains and losses between genotypes. The pathological and molecular features of hereditary breast cancer can drive specific treatments and influence the process of mutation screening. In addition, detecting molecular changes such as BRCA1/2 LOH in nonatypical cells obtained by random fine-needle aspiration, ductal lavage or nipple aspirate fluid may help to earlier identify carrier women who are at an even higher risk of developing breast carcinoma.
\end{abstract}

Modern Pathology (2005) 18, 1305-1320. doi:10.1038/modpathol.3800453; published online 3 June 2005

Keywords: hereditary breast cancer; BRCA1; BRCA2; molecular pathology; histopathology; immunohistochemistry

It is currently estimated that $5-10 \%$ of all breast cancers are hereditary and attributable to mutations in high-penetrance susceptibility genes, but only two of these have been identified: BRCA1 (OMIM 113705) $^{1}$ and BRCA2 (OMIM 600185). ${ }^{2}$ BRCA1 mutations are associated with families with breast and ovarian cancer, while families with male breast tumors are associated with mutations in the BRCA2 gene.

Correspondence: Dr J Palacios, MD, Breast and Gynaecological Cancer Group, Molecular Pathology Programme, Centro Nacional de Investigaciones Oncológicas (CNIO), Melchor Fernández Almagro No 3, Madrid 28029, Spain.

E-mail: jpalacios@cnio.es

Received 7 January 2005; revised 29 April 2005; accepted 30 April 2005; published online 3 June 2005
While early estimates suggested that BRCA1 and BRCA2 mutations were responsible for $75 \%$ of multiple-case breast cancer families and for the majority of families with multiple breast and ovarian cancers, ${ }^{3,4}$ recent data have shown that these percentages may have been overestimated. In fact, the percentage of high-risk families associated with mutations in these genes seems to be around $25 \%$ in all series investigated, including the Spanish population. ${ }^{5}$ Mutations are found in a high percentage (about $45 \%$ ) of families with breast and ovarian tumors, while the mutation rate in families with only breast cancer have a low percentage and ranges from $15 \%$ (for families with three breast cancers) to $25-35 \%$ (for families with more than five breast tumors). 
Currently, it is estimated that the proportion of breast cancer cases in the general population due to $B R C A 1$ mutations ranges from $5.3 \%$ for less than 40 years old, to $1.1 \%$ for between 50 and 70 years old. ${ }^{6}$

The penetrance of these mutations is incomplete, and depends on different factors such as the type of mutation, the population and/or exogenous factors. In general, germline BRCA1 and BRCA2 mutations confer a breast cancer risk of $80 \%$ among mutation carriers at the age of 70 years. ${ }^{7}$ Furthermore, in women with BRCA1 or BRCA2 mutations the risk of ovarian cancer is 60 and $27 \%$, respectively, at the age of 70 years. ${ }^{8-10}$ These percentages are lower in the Jewish ${ }^{11}$ and Italian ${ }^{9}$ populations, among others. The type and location of the mutation is another parameter. For instance, the missense mutations 300 $\mathrm{T}>\mathrm{G}$ in $B R C A 1$ and $4486 \mathrm{G}>\mathrm{T}$ in $B R C A 2$, have been individually found to be associated with high breast cancer risk $(P<0.001)$, and mutations in the central region of BRCA1 may be associated with a lower risk. ${ }^{12}$ Lifestyle could influence the lifetime risk in BRCA1- and BRCA2-mutation carriers. For example, physical exercise and absence of obesity in adolescence are associated with significantly delayed breast cancer onset. ${ }^{13}$

About $85 \%$ of all alterations in BRCA1 and BRCA2 tumors are frameshift or nonsense mutations, and yield a truncated protein product. The types of mutation differ in distribution by ethnicity and geographic location. For instance, the proportion of families who inherit a mutated BRCA1 gene seems to be smaller in Japanese families with breast cancer and/or ovarian cancer than in similar Eastern European families. Some mutations appear very frequently in certain populations, and are known as founder mutations. For example, the Jewish population presents a high prevalence of three mutations: 185delAG and 5382insC in BRCA1 and $6174 \mathrm{delT}$ in BRCA2. ${ }^{14}$ More than $2 \%$ of Jewish descendants carry at least one of these three mutations, and $20-30 \%$ of Jewish women diagnosed with early breast cancer are carriers of 185 delAG or 6174delT. A similar phenomenon is observed in Iceland. The prevalence of the BRCA2 cancerpredisposing mutation 999del5 in the general population has been estimated to be $0.6 \%$, and affects $7.7 \%$ of female and $40 \%$ of male patients with breast cancer. ${ }^{15}$

BRCA1 and BRCA2 are considered to be 'gatekeepers': genes whose mutation or altered expression relieves normal controls on cell division, death, or lifespan, promoting the outgrowth of cancer cells. The function of the BRCA1 and BRCA2 genes, classified as tumor suppressors, is linked with key metabolic processes such as DNA-damage repair, regulation of gene expression and cell-cycle con- trol. ${ }^{16-18}$ BRCA1 and BRCA2 act to preserve chromosome structure. Recently, several reports have provided insights into the role of BRCA1 and BRCA2 in the cellular response to DNA damage. ${ }^{19-21}$ Work by several groups ${ }^{22-24}$ has shown that BRCA1- or BRCA2-deficient rodent cells or human tumors are specifically deficient in DNA repair by homologous recombination, whereas when measured nonhomologous recombination remains intact after doublestrand DNA breaks.

There is a wide range of molecular-genetic tests for BRCA1 and BRCA2 cancer-predisposing mutations, but techniques based on sequencing and Denaturing High-Performance Liquid Chromatography or Denaturing Gradient Gel Electrophoresis offer the greatest accuracy. However, these techniques are expensive, complex and time consuming due to the large size of both genes. For this and other reasons, such as the absence of hotspots for mutations in their coding regions and the low percentage of mutated cases, it is necessary to select good candidate families for mutation testing. Until now such selection has been based on clinical criteria, but the function of these genes and the pathology of their tumors is now been established and this information could also be used to select candidate families.

In recent years, it has been demonstrated that breast cancer arising in mutation carriers of $B R C A 1$ and BRCA2 genes differs from sporadic breast cancer of age-matched controls and from nonBRCA1/2 familial breast carcinomas in their morphological, immunophenotypic and molecular characteristics. The recognition of these differences, in addition to improving our understanding of the biology of hereditary breast cancer, could be used to predict $B R C A$ mutation status in a given patient. In addition, these features could also be used to select the most appropriate treatment for an affected woman. The aim of this review is to set out our current knowledge of the morphological, immunohistochemical and molecular characteristics of $B R C A 1, B R C A 2$ and non-BRCA1/2 hereditary breast cancer, and to describe how these characteristics may impact on genetic testing and treatment.

\section{Histopathology of BRCA1 and BRCA2 Breast Cancer}

\section{Invasive Carcinoma}

The histopathology of BRCA-associated cancer has been studied by different groups. The largest series is that reported by the Breast Cancer Linkage Consortium (BCLC). ${ }^{25-27}$ Their studies have demonstrated that cancer arising in carriers of BRCA1 and

Figure 1 Typical histological patterns of BRCA1, BRCA2 and non-BRCA1/2 tumors: (a) Necrosis area, (b) pushing margins, (c) prominent lymphoid infiltration, (d) solid sheets with high pleomorphism and numerous mitosis, (e) in situ ductal carcinoma (more frequent in $B R C A 2$ and non-BRCA1/2 tumors), and (f)-(h) tumors with well-formed tubules, low pleomorphism and low number of mitosis. 

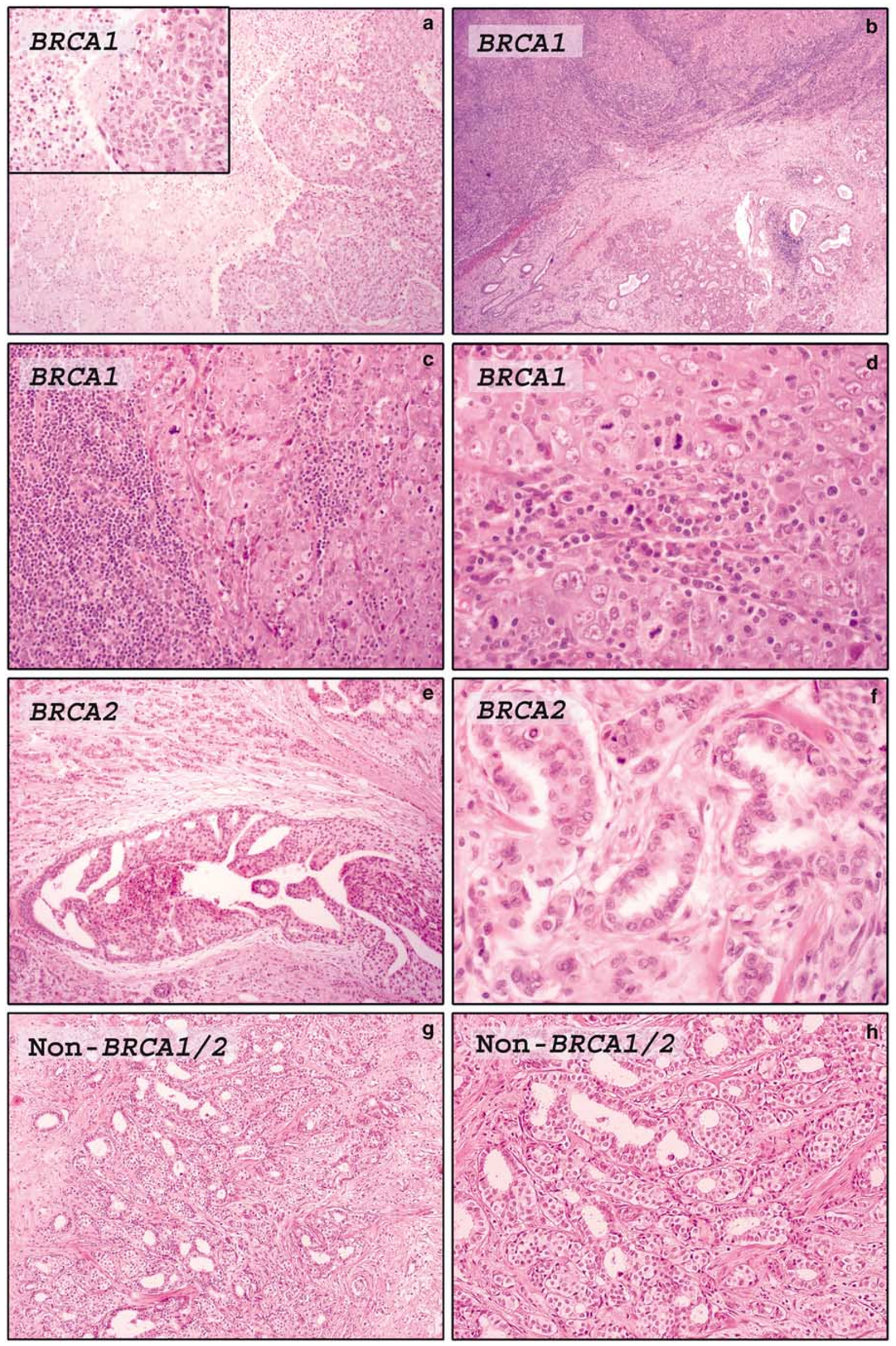
BRCA2 gene mutations differs morphologically from sporadic breast cancer of age-matched controls. ${ }^{26-29}$ Invasive ductal carcinoma-not otherwise specified is the most common histological type in all forms of hereditary breast cancer and seems to be significantly more frequent in BRCA1- and BRCA2-mutation carriers than in noncarriers. ${ }^{30}$ In addition, BRCA1-mutation carriers have a higher incidence of medullary carcinoma $(13 \%)$ than BRCA2-mutation carriers $(3 \%)$ and noncarriers $(2 \%){ }^{27}$ When only invasive ductal carcinomas are compared, after excluding medullary carcinomas, BRCA1 tumors more frequently have a prominent lymphocytic infiltrate, foci of necrosis and pushing margins, ${ }^{26}$ which are some of the features that define the medullary histotype (Figure 1).

Several studied series exhibited no statistically significant difference in the histological type of BRCA2 tumors and controls. ${ }^{26,27,31}$ However, Marcus et $a l^{32}$ reported a higher incidence of BRCA2 tumors belonging to a 'tubular lobular group', including invasive lobular, tubular and cribriform carcinomas. ${ }^{32,33}$ Armes et $a l^{28}$ found that BRCA2-mutation carriers showed an excess of pleomorphic lobular and intraductal carcinomas. It remains to be established whether differences between series are due to the ethnicity of specific mutations.

One of the most constant characteristics of BRCA1 tumors is their high histological grade. Thus, the reported incidence of grade 3 tumors in BRCA1mutation carriers ranged from 66 to $84 \%$ in different studies, ${ }^{27,34-36}$ while the proportion of grade 3 tumors in sporadic age-matched breast cancer controls was between 30 and $40 \%{ }^{27,34-36}$ BRCA1 tumors show less tubule formation, higher pleomorphism and more mitosis than do sporadic age-matched breast cancer controls.

BRCA2 tumors tend to be of higher grade than sporadic controls, although this association is less strong than for BRCA1 cases. Most BRCA2 tumors are grade $2 / 3$, and show less tubule formation but cellular pleomorphism and mitotic counts similar to those of sporadic cases. ${ }^{27}$ However, in some series more nuclear pleomorphism and higher mitotic rates have been reported in BRCA2 tumors than in sporadic tumors $^{31}$ (Table 1).

Many series have demonstrated a high frequency of estrogen receptor-negativity in BRCA1 tumors. $^{25,34,35,37-41}$ Between 73 and $90 \%$ of BRCA1 carcinomas were estrogen receptor-negative in different series. ${ }^{34,35,38}$ For example, Lakhani et $a l^{25}$ reported that $90 \%$ of BRCA1-related breast cancers were estrogen receptor-negative compared with $35 \%$ in controls. Although it has been suggested that this relationship might be explained by the higher grade of tumors and younger age of patients, BRCA1 tumors are more likely to be estrogen receptornegative than are sporadic ones, when tumors from patients of the same age are compared. In addition, the likelihood of estrogen receptor-negativity is 4.8 times higher in BRCA1 grade 3 tumors than in grade 3 sporadic cases. $^{37}$

Progesterone receptor expression in BRCA1 tumors is also lower than in sporadic tumors. In the study of Lakhani et $a l^{25} 79 \%$ of BRCA1 tumors were progesterone receptor-negative, compared with only $41 \%$ in sporadic tumors. The same proportion has been observed in other studies ${ }^{34,35,38}$ (Figure 2).

In contrast to BRCA1 tumors, those arising in BRCA2-mutation carriers do not differ from controls with regard to estrogen receptor and progesterone receptor expression. Thus, estrogen receptor expression has been reported in around $65 \%$ of $B R C A 2$ tumors. ${ }^{25,38,39}$ Between 40 and $60 \%$ of BRCA2 carcinomas express progesterone receptor ${ }^{25,38,39}$ (Table 2).

\section{Non-Invasive Lesions}

Regarding precursor lesions, the natural history of hereditary breast cancer, from morphologically normal epithelium to invasive disease, is not well understood. The incidence of in situ lesions associated with invasive carcinomas is not described in most publications. Overall, an in situ component is rarer around invasive ductal carcinomas in BRCA1mutation carriers than in controls. ${ }^{27}$ In addition, the

Table 1 Histological characterization of familial and sporadic breast tumors

\begin{tabular}{|c|c|c|c|c|c|}
\hline & $B R C A 1(\%)$ & BRCA2 (\%) & Non-BRCA1/2 (\%) & Sporadic tumors (\%) & References \\
\hline Invasive lobular carcinoma & 7 & 13 & 14 & 12 & $30,33,34,36,67,95$ \\
\hline Invasive ductal carcinoma & 74 & 71 & 73 & 69 & $30,33,34,36,67,95$ \\
\hline Medullary carcinoma & 18 & 3 & 2 & 3 & $28,30,33,36,67,95$ \\
\hline Grade 3 & 71 & 39 & $2 \overline{2}$ & 36 & $\begin{array}{l}28,30,31,33,34 \\
35,36,67,95\end{array}$ \\
\hline Mitotic count (score 3) & 74 & 45 & 17 & 33 & $28,31,33,34,95$ \\
\hline Tubules (score 3) & 81 & 70 & 59 & 65 & $28,31,33,34,95$ \\
\hline Pleomophism (score 3) & 76 & 46 & 35 & 56 & $28,31,33,34,95$ \\
\hline Pushing margins $>75 \%$ & 49 & 16 & 5 & 27 & 28,95 \\
\hline Solid sheets $>75 \%$ & 30 & 12 & 8 & 10 & 95 \\
\hline Prominent lymphoid infiltration & 13 & 3 & 6 & 6 & 95 \\
\hline Necrosis & 71 & 21 & 13 & 23 & 95,28 \\
\hline
\end{tabular}


$B R C A 1$
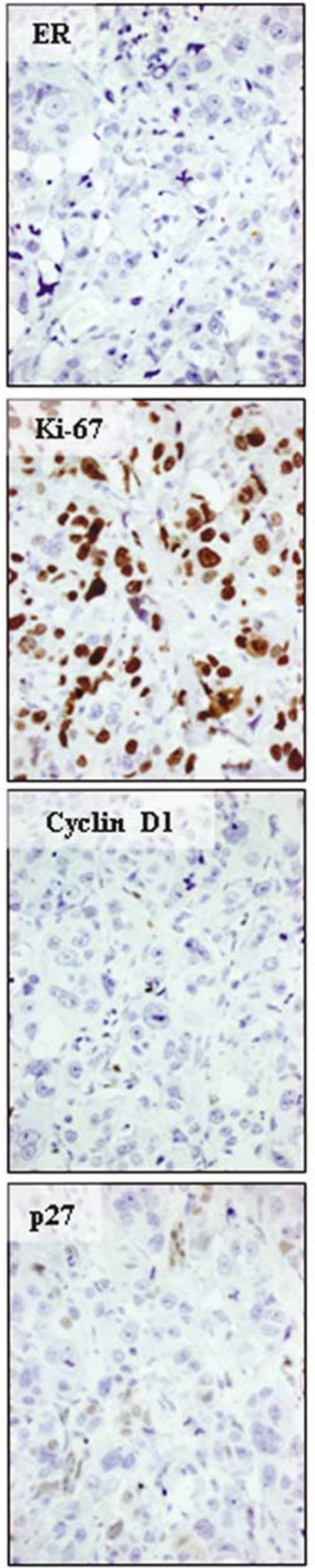
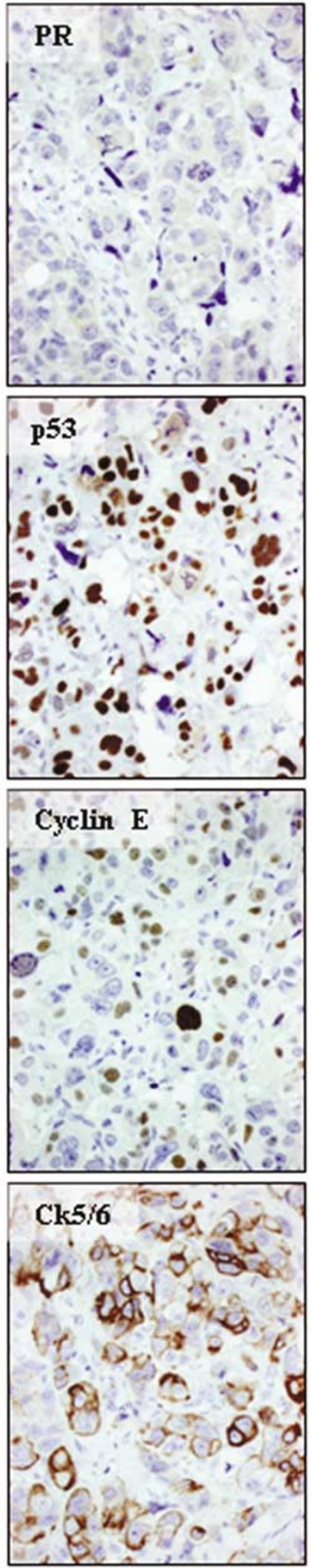
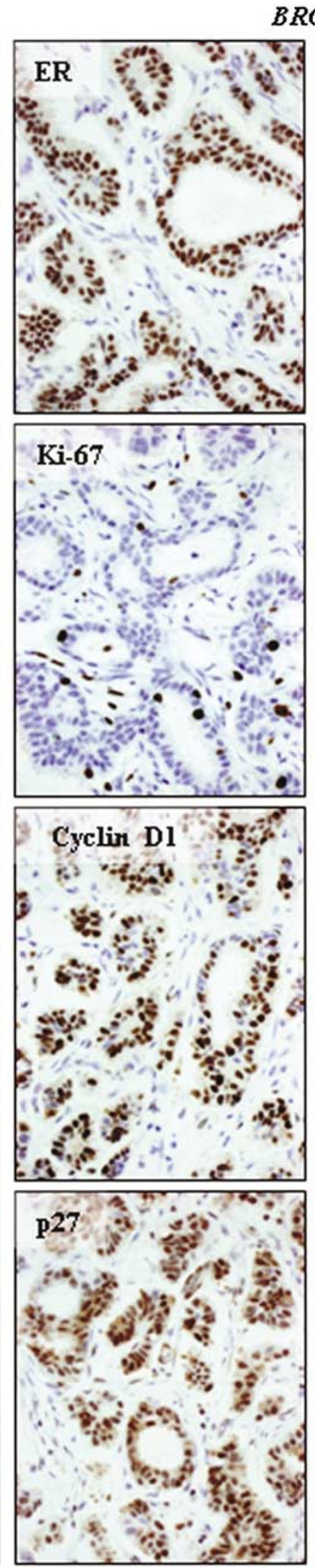

$B R C A 2$
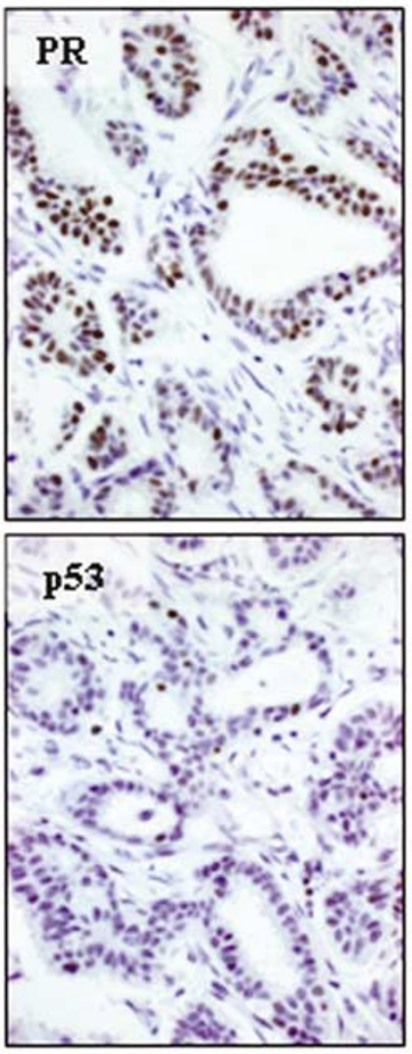

\section{Cyclin E}
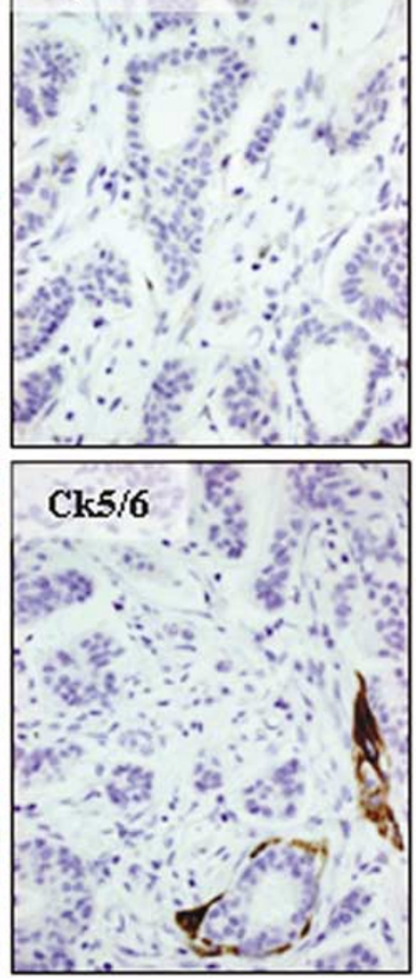

Figure 2 Immunohistochemical features of BRCA1 and BRCA2 breast carcinomas. 
Table 2 Immunohistochemical characterization of familial and sporadic breast tumors

\begin{tabular}{|c|c|c|c|c|c|}
\hline & BRCA1 (\%) & BRCA2 (\%) & Non-BRCA1/2 (\%) & Sporadic tumors (\%) & References \\
\hline Estrogen receptor+ & 21 & 65 & 72 & 66 & $\begin{array}{l}30,34,36-39 \\
25,35,67\end{array}$ \\
\hline Progesterone receptor + & 20 & 49 & 60 & 56 & $25,30,34-36,38,67$ \\
\hline Ki-67+ & 56 & 21 & 7 & 22 & $34,38,67$ \\
\hline p53+ & 45 & 27 & 12 & 27 & $25,30,34-36,38,67$ \\
\hline HER2+ & 7 & 6 & 3 & 18 & $25,34-36,67$ \\
\hline Cyclin D1+ & 30 & 56 & - & 79 & $67,38,69$ \\
\hline Cyclin E+ & 47 & 35 & - & 27 & 69 \\
\hline p27+ & 40 & 85 & - & 60 & 69 \\
\hline Ck5/6+ & 65 & 7 & - & 8 & 91,92 \\
\hline
\end{tabular}

incidence of in situ lesions in the absence of an invasive component in familial breast cancer has not been established.

The study of prophylactic mastectomy specimens from BRCA1/2-mutation carriers has been proposed as a means to better understand the different stages of breast cancer development in these patients. However, the few data so far available are not conclusive because of the small number of case studies involved, and the difficulty of selecting appropriate controls and recognizing precursor lesions.

Hoogerbrugge et al have reported a study of 67 patients at high risk of breast cancer, 44 of whom had BRCA mutations and underwent unilateral or bilateral prophylactic mastectomy. One or more different types of high-risk precursor lesions, such as atypical lobular hyperplasia, atypical ductal hyperplasia, lobular carcinoma in situ and ductal carcinoma in situ, were present in $57 \%$ of the women. High-risk lesions were more frequent in the group aged 40 years than in the older group (73 vs $43 \%)$ and less frequent in BRCA-mutation carriers $(43 \%)$ and women with bilateral oophorectomy before prophylactic mastectomy (20\%). ${ }^{42}$

In another study, Kauff et $a l^{43}$ compared prophylactic mastectomy specimens from 24 women with $B R C A$ mutations and 48 controls extracted from an autopsy registry, and concluded that BRCA-mutation carriers have a higher incidence of high-risk lesions $(46 \%)$ than control cases $(6 \%)$. Adem et $a l^{44}$ compared prophylactic mastectomy in patients with a family history of breast cancer including 28 BRCA1/2-mutation carriers, 117 women without BRCA1/2 mutations, 12 unclassified mutation variant carriers and 283 sporadic control cases. They found a similar prevalence of ductal carcinoma in situ in all groups (50-60\%); however, in BRCA1/2mutation carriers, proliferative fibrocystic changes were less prevalent $(7 \%)$ than in sporadic cases $(25 \%)$. By contrast, the proportion of invasive carcinomas was higher in mutation carriers and unclassified mutation variant-carriers than in the control group and the group without mutations, suggesting a faster progression of precursor lesions in mutation carriers.

\section{Molecular alterations in BRCA1 and BRCA2 breast cancer}

\section{LOH at BRCA1 and BRCA2 Loci and Other Chromosome Alterations}

The BRCA genes act as classical tumor suppressors, since they are nonfunctional in cancer cells as a result of germline mutations following inactivation of the second allele in the tumor (the Knudson twohit hypothesis). Given that somatic mutations in the $B R C A$ genes were rarely found in hereditary tumors, ${ }^{45}$ it was suggested that somatic loss of the wild-type allele is a common mechanism of tumor activation. This hypothesis has been supported by several studies of loss of heterozygosity (LOH) in $B R C A 1$ and BRCA2 loci in tumors from mutation carriers. For example, Staff ${ }^{46}$ found BRCA1 LOH in all informative tumors from BRCA1-mutation carriers (15/15) and BRCA2 $\mathrm{LOH}$ in five out of six informative tumors from BRCA2-mutation carriers. Similarly, Osorio et $a l^{47}$ found BRCA1 LOH in nine out of 10 tumors from $B R C A 1$-mutation carriers, and in five out of six tumors from BRCA2-mutation carriers. Armes et $a l^{38}$ identified $B R C A 1 \mathrm{LOH}$ in seven out of eight informative cases of tumors from BRCA1-mutation carriers, and in each of seven tumors from BRCA2-mutation carriers. Interestingly, these authors studied the in situ component in three and five BRCA1 and BRCA2 tumors, respectively, and found the same allele to be lost as in the invasive component in all but one BRCA2 ductal carcinoma in situ, which did not show LOH. Finally, Cavalli et $a l^{48}$ found LOH of the corresponding wildtype allele in six tumors from five BRCA1- and one BRCA2-mutation carriers. In the latter study, the authors analyzed not only tumor tissue, but also non-neoplastic adjacent tissues, including normal lobules and sclerosing adenoses, and observed $B R C A 1 / 2 \mathrm{LOH}$ in all six cases. In some women, $\mathrm{LOH}$ was detected not only in peritumoral areas but also in other quadrants, and even in the contralateral breast. These findings suggested that these nonmalignant tissues already harbor significant amounts of the genetic alterations that may predispose to malignant transformation. 
It has been demonstrated that BRCA1 promoter hypermethylation may be a second inactivation event in BRCA1 families, but this mode of inactivation is infrequent due to the dominance of genetic deletions as 'second hits'. ${ }^{49}$

Staff et $a l^{46}$ reported that the somatic loss of the other cancer susceptibility gene locus might be selected in cancer development in tumors from BRCA1/2-mutation carriers. They used microsatellite analysis and Fluorescence in situ hybridization (FISH) to study somatic loss of BRCA1 in breast tumors from BRCA2-germline mutation carriers and vice versa. They found that eight out of eleven $(73 \%)$ informative tumors from BRCA1mutation carriers had BRCA2 $\mathrm{LOH}$, and that five out of six informative tumors from BRCA2-mutation carriers had BRCA1 LOH. Combined LOH in $B R C A 1$ and BRCA2 genes was seen in twelve of the $17(71 \%)$ informative hereditary breast tumors, whereas this situation was only seen in 32 and $47 \%$ (Silva $^{50}$ and Kelssel, ${ }^{51}$ respectively) of sporadic tumors (Table 3).

Comparative genomic hybridization analysis has demonstrated that breast tumors from $B R C A 1$ and BRCA2-germline mutation carriers contain a large number of chromosomal copy number gains and losses. Tirkkonen et al ${ }^{52}$ carried out a genome-wide survey by comparative genomic hybridization on breast cancers from 21 BRCA1-mutation carriers, 15 BRCA2-mutation carriers, and 55 unselected controls. The total number of genetic changes was almost twice as high in tumors from both BRCA1and BRCA2-mutation carriers as in the control group. In $B R C A 1$ tumors, losses of $5 \mathrm{q}(86 \%), 4 \mathrm{q}$ $(81 \%), 4 p(64 \%), 2 q(40 \%)$, and $12 q(40 \%)$ were significantly more common than in the control group (7-13\%). BRCA2 tumors were characterized by a higher frequency of $13 q(73 \%)$ and $6 q(60 \%)$ losses and gains of 17q22-q24 (87\%) and 20q13 $(60 \%)$ compared to the prevalence of these changes in the control group (12-18\%).

Wessels et $a l^{53}$ studied a series of 28 BRCA1 and 42 control breast carcinomas by comparative genomic hybridization and found that at the chromosome level, BRCA1 tumors showed more frequent loss of $3 p, 4 p, 5 q, 12 q, 16 p$, and $18 q$ and gain of chromosome arms 3q, 7p, 8q, 10p, and 12p. Control tumors featured more frequent gain of $16 p$ and 17q. The authors developed a molecular classifier, which assigns a given tumor to either the BRCA1 or control group based on somatic genetic profiles with an accuracy of $84 \%$ (sensitivity of $96 \%$ and specificity of $76 \%$ ). Chromosomal bands used by this classifier include regions on chromosomes 3p, 3q, and $5 q$.

High-resolution comparative genomic hybridization has been used to build a classifier that allows to differentiate BRCA1 and BRCA2 tumors. ${ }^{54}$

Together, these data imply that accumulation of somatic genetic changes during tumor progression may follow a unique pathway in individuals genetically predisposed to cancer, especially in the case of the BRCA1 gene. Activation or loss of genes in the affected chromosomal regions may be selected for during tumor progression in cells lacking functional BRCA1 or BRCA2.

\section{p53 Expression and Gene Mutations}

Around $15-30 \%$ of sporadic breast carcinomas have mutations in the tumor-suppressor gene p53. Most of them are missense mutations and produce accumulation of stable p53 protein that can be visualized by immunohistochemistry. However, $20 \%$ of the mutations do not yield a stable protein and are not detected by immunostaining. For this reason, there is a stronger association between clinicopathological variables and p53 mutations detected by DNA sequencing than with p53 immunohistochemistry detection in breast cancer.

Considering the proposed function of BRCA1/2 in DNA double-strand break repair, it was suggested that loss of BRCA1/2 function activates a p53dependent checkpoint that prevents genomic instability by promoting cell-cycle arrest or apoptosis. Abrogation of this checkpoint might be essential for malignant transformation in cells with BRCA1/2inactivation and could be brought about by mutation of $p 53$.

Several studies have demonstrated a higher incidence of p53 immunostaining in BRCA1 than

Table 3 Molecular characterization of familial and sporadic breast tumors

\begin{tabular}{|c|c|c|c|c|c|}
\hline & BRCA1 (\%) & BRCA2 (\%) & Non-BRCA1/2 (\%) & Sporadic tumors (\%) & References \\
\hline p53 mutation & 62 & 46 & - & 28 & $30,55,56$ \\
\hline HER2 amplification & 6 & 0 & 5 & 19 & $34,61,62$ \\
\hline CCND1 amplification & 18 & 60 & - & 20 & 34 \\
\hline$C C N E$ amplification & 0 & 0 & - & 0 & 34 \\
\hline MYC amplification & 26 & 35 & 12 & 21 & $34,62,63$ \\
\hline MYB amplification & 29 & 0 & - & 2 & 64 \\
\hline BRCA1 LOH & 92 & 83 & 6 & 47 & $38,46,47,50$ \\
\hline$B R C A 2 \mathrm{LOH}$ & 73 & 89 & - & 51 & $38,46,47,50$ \\
\hline Chromosome gains & $3 q, 7 p, 8 q, 10 p$ & $17 q 22-24,20 q 13$ & $1 q, 17 q, 8 q, 16 p$ & $8 q, 17 q, 16 p, 10 p$ & $52,53,98$ \\
\hline Chromosome losses & $3 p, 5 q, 4 q, 4 p, 2 q$ & $6 q, 13 q$ & $13 q, 6 q, 11 q, 9 p, X p$ & $5 q, 4 p, 3 p$ & $52,53,98$ \\
\hline
\end{tabular}


in sporadic cases. p53 overexpression has been detected in $45-77 \%$ of BRCA1-associated tumors. ${ }^{25,34,35,55,56}$ The results in BRCA2 tumors are less conclusive. ${ }^{25}$ Some studies have found p53 overexpression in around $50 \%$ of BRCA2 carcinomas, whereas the percentage was lower than $20 \%$ in other series. ${ }^{34}$

The importance of p53 inactivation in BRCAassociated tumors is also demonstrated by genetic studies in which p53 mutations were present at higher frequencies and in unusual locations in this group compared with sporadic cases. ${ }^{55-57}$ In a review of reported cases by Chappuis et al, ${ }^{30}$ around $40 \%$ of $B R C A 1$ and $30 \%$ of BRCA2 carcinomas had p53 mutations, whereas only $20 \%$ of sporadic controls had them. However, p53 mutations were not found in BRCA2 tumors in one series. ${ }^{38}$

Comparing the spectrum of p53 mutations in BRCA1/2 patients with the mutations reported in the IARC p53 mutation database, Greenblatt et al ${ }^{58}$ found that they differed significantly in distribution and base change. Mutations at A:T base pairs were more common in BRCA1/2-associated tumors (38\%) than in the IARC database (25\%). Changes were frequent at $p 53$ codons that are not mutation hotspots. Thus, in the IARC database, mutations in 73 hotspot codons accounted for $82 \%$ of all cases of breast cancer, but in BRCA1/2-mutation carriers only $67 \%$ occurred at these hotspots. Finally, most nonhotspot mutations in BRCA1/2-mutation carriers were located on the opposite side of the p53 DNAbinding site. Interestingly, Greenblatt et al ${ }^{58}$ found no differences in the spectrum and location of $p 53$ mutations between BRCA1 (44 mutations) and BRCA2 (29 mutations) tumors.

Functional characterization of specific mutations of BRCA1/2 tumors has revealed that they frequently possess properties not commonly associated with those occurring in sporadic cases: they retain apoptosis-inducing, transactivating, and growth-inhibitory activities similar to those of the wild-type protein, yet are compromised for transformation suppression. It has been suggested that the BRCAassociated mutants represent the minimal loss of function required to overcome p53-dependent tumor suppression. The genetic background in $B R C A$ null cells would allow the selection of $p 53$ mutants whose expression is not tolerated in cells with intact BRCA1/2 genes. ${ }^{59}$

\section{HER2 Expression and Gene Amplification}

Data on HER2 expression in BRCA-associated tumors vary from series to series, probably as a consequence of differences in the techniques employed. For example, Armes et $a l^{38}$ found no differences in the strong expression of HER2 in BRCA2 and sporadic breast tumors (44 and 45\%, respectively), but did not find HER2 expression in any BRCA1 tumors. However, subsequent studies revealed frequencies of $0-3 \%$ in HER2 overexpression in both BRCA1 and BRCA2 tumors. ${ }^{25,34,60}$

With regard to HER2 amplification, few studies have analyzed gene status by FISH in hereditary BRCA1/2-associated carcinomas. ${ }^{34,61}$ Grushko et al ${ }^{61}$ reported that 10 out of $53(19 \%)$ BRCA1 tumors had a HER2:CEP17 ratio $\geq 2$. The mean HER2:CEP ratio was $2.4 \pm 0.4$, and never exceeded 3.1. The tumors were therefore categorized as having low levels of amplification. The authors also found that that the majority of tumors from BRCA1-mutation carriers (32 of 53;61\%) were monosomic for chromosome 17 , and $19 \%$ were polysomic. Palacios et $a l^{34}$ and Adem et $a l^{62}$ did not find any HER2-amplified cases in a sample of 43 BRCA1/2 carcinomas. Apart from amplification, other chromosome aberrations involving chromosome 17 were observed in one of these studies, ${ }^{34}$ polysomy was observed in two $(20 \%)$ $B R C A 2$ carcinomas and monosomy was observed in five (35\%) BRCA1 carcinomas. The different types of chromosomal abnormalities in different genotypes may be relevant, since chromosome 17 monosomy may be the second hit of inactivation in a proportion of BRCA1-associated carcinomas. It has been suggested that the low incidence of HER2 amplification in BRCA1 carcinomas may be due to a physical codeletion of one HER2 allele and nearby sequences during the $\mathrm{LOH}$ at the $B R C A 1$ locus. ${ }^{61}$ At present, there is no plausible explanation for the low incidence of HER2 amplification in BRCA2 carcinomas.

\section{$M Y C$ and $M Y B$ Amplification}

Three studies have reported different frequencies of $M Y C$ amplification in BRCA1/2 hereditary breast cancer. However, due to differences in the methodologies used (tissue microarrays vs whole sections) and the genotypes analyzed (BRCA1 only, BRCA1 and BRCA2, and BRCA1/2 as a group), it is not clear whether or not $M Y C$ status differs among BRCA1, $B R C A 2$, and sporadic breast carcinomas.

Grouskko et $a l^{63}$ observed that 21 out of 40 (57\%) tumors from BRCA1-mutation carriers had $M Y C$ amplification defined as a $M Y C$ :CEP8 ratio of $\geq 2$; most of these cases had two to four copies. They also found that most $M Y C$-amplified cases had chromosome 8 polysomy. In another study, ${ }^{34}$ although there were too few cases (10 BRCA1, 8 BRCA2), differences were observed between genotypes, whereby MYC amplification was observed in two (18\%) $B R C A 1$, in five $(62 \%) B R C A 2$, and in two $(12 \%)$, non-BRCA1/2 invasive ductal carcinomas. Two polyploid cases were observed in BRCA1 tumors. No cases showed amplification of both HER2 and MYC. These results are in contrast to those obtained by Adem et $a l,{ }^{62}$ who found a high prevalence of MYC duplications (57\%) but a low frequency of amplification (8\%) among invasive carcinomas from BRCA1/2-deleterious mutation carriers. 
A high regional copy number gain at 6q22-q24 was revealed in BRCA1 tumors using comparative genomic hybridization. ${ }^{64}$ FISH analysis revealed amplification of $M Y B$ in five (29\%) of 17 BRCA1 breast tumors, whereas none of eight BRCA2 tumors and 13 breast cancer cell lines, and only two of 100 sporadic breast tumors exhibited altered MYB copy numbers. Gene amplification resulted in mRNA overexpression, as determined by Northern blot and cDNA microarray analysis, and in protein overexpression, as determined by immunohistochemical staining. The authors concluded that $M Y B$ amplification is infrequent in sporadic breast cancer but common in breast tumors from BRCA1mutation carriers, suggesting a role for this cellcycle regulator and transcription factor in the progression of some BRCA1 tumors.

\section{Alterations in Cell-Cycle Regulation}

Proliferation rate, gauged through mitotic counts and Ki67 immunostaining, was one of the most important characteristics differentiating familial and sporadic breast cancer, ${ }^{26,65}$ suggesting that the expression of genes involved in cell-cycle control differs between genotypes. Cell-cycle progression is governed by cyclin-dependent kinases (CDKs) that are activated by cyclin binding and inhibited by CDK inhibitors (CDKI). ${ }^{66}$ The passage from $\mathrm{G}_{1}$ to $\mathrm{S}$ phase is regulated by the activities of cyclin D1/CDK4, cyclin E/CDK2, and cyclin A/CDK2 complexes. Cyclin $B / C D K 1$ regulates the $G_{2}-M$ transition. Two CDKI families regulate the cell-cycle. Members of the CDK4 (INK4) inhibitor family, such as $\mathrm{p} 15^{\mathrm{INK} 4 \mathrm{~B}}$ and $\mathrm{p} 16^{\mathrm{INK} 4 \mathrm{~A}}$, inhibit and specifically bind to CDK4 and CDK6. In contrast, members of the kinase inhibitor protein (KIP) family (p21 ${ }^{\mathrm{CIP} 1}$, $\mathrm{p} 27^{\mathrm{Kip} 1}$, and $\mathrm{p} 57^{\mathrm{Kip} 2}$ ) have opposite effects on the function of different CDKs. While p27 and p21 have a negative effect on cyclin E/CDK2 and cyclin A/CDK2 activity, they seem to activate cyclin D/CDK complexes. ${ }^{66}$

The expression of these cell-cycle proteins has been extensively studied in sporadic breast cancer and in most cases each marker has been associated with specific morphological (histological grade) or biological (estrogen receptor status) characteristics. However, hereditary breast cancer studies are uncommon and generally limited to the analysis of the expression of individual cell-cycle proteins. ${ }^{38,40,41,67}$ The expression of cyclin D1 has been reported in some series, but there is little information available for most of the other cell-cycle markers. ${ }^{38,41,67}$ Most series have exhibited lower cyclin-D1 expression levels in BRCA1 than in sporadic tumors. ${ }^{38,40,68}$ Cyclin-D1 expression in BRCA2 tumors has been found at an intermediate level between those of BRCA1 and sporadic tumors. For example, Osin et $a l^{40}$ reported that cyclin D1 was expressed in $27 \%$ of BRCA2 tumors, compared with $5 \%$ in BRCA1 tumors and $35 \%$ in sporadic tumors. Likewise,
Armes et $a l^{38}$ showed cyclin D1 positivity in 55\% of BRCA2, $33 \%$ of BRCA1 and $100 \%$ of sporadic tumors. In a previous study, our group found that 5 , 57 , and $56 \%$ of BRCA1, BRCA2, and sporadic agematched controls, respectively, showed cyclin D1 expression in more than $50 \%$ of neoplastic cells. ${ }^{69} \mathrm{In}$ support of these results, a lower incidence of cyclin D1 expression in BRCA1 than in BRCA2 carcinomas was also revealed by cDNA microarray analysis. $^{38,67,70}$ This is not surprising, considering that cyclin D1 is a protein induced by estrogen, and its association with estrogen receptor positivity has been clearly demonstrated in breast cancer.

CCND1 amplification associated with cyclin D1 overexpression has been reported in around $20 \%$ of sporadic breast cancers. Vaziri et $a 7^{71}$ used FISH to study CCND1 amplification in 30 tumors from BRCA1-mutation carriers and did not find any amplified cases. In contrast, Palacios et al ${ }^{69}$ identified five cases of CCND1 amplification among 16 $B R C A 1 / 2$ cases. The incidence of gene amplification in BRCA1 tumors (two out of $11 ; 18 \%$ ) was similar to that previously reported in sporadic cases. In $B R C A 2$ tumors, although the frequency of this alteration was very high (three out of five; $60 \%$ ), the small number of valuable cases precluded any conclusion regarding whether or not this molecular alteration is characteristic of this breast cancer phenotype.

In our previous study, differences between $B R C A 1$ and $B R C A 2$ hereditary breast carcinomas in the expression of cell-cycle molecules were observed not only for cyclin D1, but also for its associated CDK (CDK4) and CDKIs (p16, p21, p27), which were downregulated in BRCA1 with respect to BRCA2 carcinomas. For example, only eight out of 20 BRCA1 tumors showed p27 expression in more than $50 \%$ of the tumor cells; by contrast, 12 out of 14 (86\%) BRCA2 tumors did. In addition, the expression of p27 was associated with estrogen receptor status, as previously reported in sporadic tumors. Conversely, Chappuis et $a l^{72}$ found that in 27 $B R C A 1 / 2$-mutation carriers, the frequency of lowlevel p27 expression (less than $50 \%$ of stained cells) was $85 \%$ (23 of 27 ), compared with $59 \%$ (87 of 147) in noncarriers of BRCA1/2 mutations. When BRCA1and BRCA2-related breast cancers were analyzed separately, a low p27 expression level was present in all seven $(100 \%)$ breast cancers in BRCA2mutation carriers and in $16(80 \%)$ of the 20 breast cancers in BRCA1-mutation carriers. With regard to estrogen receptor status, they found that all the BRCA2-associated breast cancers that were evaluated had low levels of p27 expression, despite the fact that six of these seven tumors were estrogen receptor-positive. The authors suggested that the association between low $\mathrm{p} 27^{\mathrm{Kip} 1}$ expression and $B R C A 1 / 2$ germline mutations in hereditary breast cancer does not necessarily result from alteration of the estrogen receptor pathway. Differences between studies could be related with ethnicity, since 


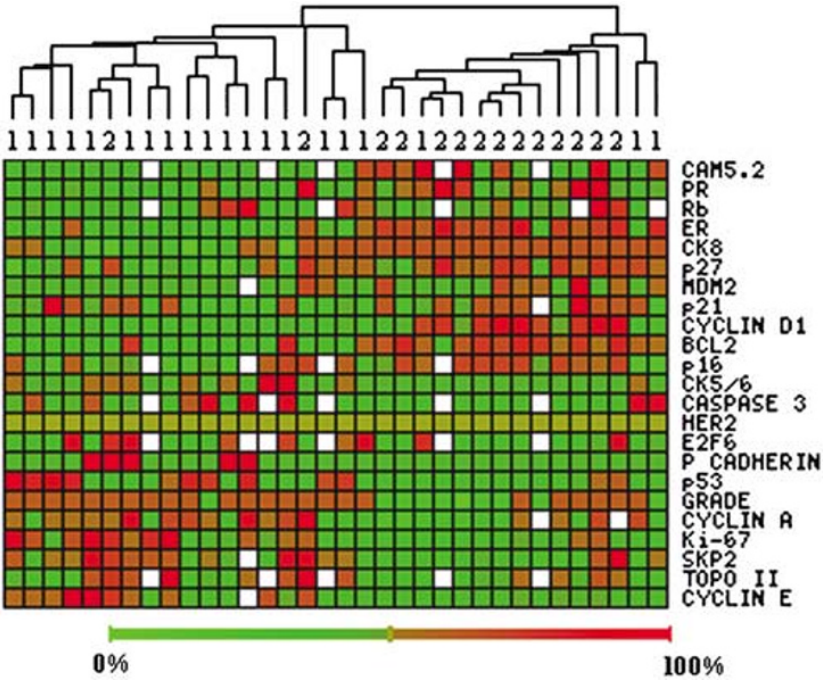

Figure 3 Differential expression profiles of BRCA1 vs BRCA2 tumors. Using the immunohistochemical expression of the markers shown on the right, the majority of the BRCA1 tumors (1) were grouped in a separate cluster from the BRCA2 tumors (2). The basal phenotype characterized by CK 5/6- and cyclin Epositivity and estrogen receptor, HER2-, and p27-negativity is observed in BRCA1 tumors. Red indicates positive expression, green indicates negative expression, and the intensity of the color is a function of the immunohistochemical expression level. White indicates expression not valuable.

Chappuis et $a l^{72}$ studied only Ashkenazi Jewish women with primary invasive breast cancer due to the three common BRCA1/2 founder mutations present in this population.

In our cluster analysis of several cell-cycle proteins, markers associated with a BRCA1 phenotype were cyclins A, B1, and E, and SKP2, among others (Figure 3). Cyclin E has also been related with the BRCA1 phenotype in an additional study. ${ }^{73}$ Interestingly, we have not detected any $B R C A 1 / 2$ carcinoma showing $C C N E$ amplification, ${ }^{34}$ indicating that in hereditary breast carcinoma CCNE amplification is a rare event, as previously reported for sporadic cases. $^{74}$ Based on their cell-cycle regulatory defects, the phenotypes of $B R C A 1$ and BRCA2 carcinomas are similar to those proposed by Landberg, ${ }^{75}$ but with fewer markers differentiating at least two subgroups of sporadic breast cancer. One of them, the BRCA2 carcinomas, was characterized by estrogen receptor-positivity and high cyclin D1 and p27, and seemed to induce cell proliferation through a preserved $\mathrm{Rb}$ pathway. The second group, the BRCA1 carcinomas, was estrogen receptornegative, and showed defects in p53 and p27. These tumors had a more substantial lack of G1/S control, adopting an $\mathrm{Rb}$-independent mechanism of cell proliferation. ${ }^{68}$

\section{Alterations in Apoptosis Regulation}

Dysregulation of apoptosis plays an important role in the pathogenesis and progression of breast cancer, as well as in responses of tumors to therapeutic intervention. Overexpression of BCL2 is commonly observed in estrogen receptor-positive sporadic breast carcinomas and has been associated with a good prognosis. ${ }^{76}$ Compared with BCL2, far less is known about the expression of other apoptotic markers in breast tumors in general, and in hereditary cases in particular.

Overexpression of BCL2 in BRCA2 tumors has been reported in several studies, confirming the good correlation between these markers and estrogen receptor status. ${ }^{77}$ By contrast, low levels of BCL2 but high levels of caspase 3 were observed in BRCA1 tumors. ${ }^{34}$ Caspase 3 is a cytosolic enzyme that is activated only in cells committed to undergoing apoptosis, and is strongly associated with morphological assessment. Thus, previous studies have shown that the apoptotic index obtained by measuring caspase activation was higher in high-grade, estrogen receptor-negative tumors, ${ }^{78}$ as has been observed in BRCA1-associated carcinomas. These data are in accordance with an expression study using cDNA microarrays that showed BRCA1-mutation-positive tumors to have increased expression of genes associated with inducing apoptosis (such as PDCD5), and decreased expression of genes involved in suppressing apoptosis (such as $C T G F) .{ }^{70}$

\section{BRCA1 Carcinomas and the Basal Cell Phenotype}

Expression studies using conventional immunohistochemistry on whole sections ${ }^{79-81}$ tissue microarray immunohistochemistry, ${ }^{82-84}$ and cDNA-array technology ${ }^{85,86}$ have demonstrated that there is a subset of breast carcinomas that express the socalled 'basal cell' or myoepithelial markers, such as high molecular weight cytokeratins (CK) CK5/6, CK14 and CK17, and P-cadherin. These reports have established that breast carcinomas with expression of basal cell markers show specific characteristics in relation to their morphological, proliferative, and prognostic characteristics. Several studies have linked the expression of basal markers to increased proliferation, absence of ER, a characteristic growth pattern, and poor prognosis. ${ }^{79,80,87,88}$ Recently, Sorlie et $a l,{ }^{89}$ reanalyzing cDNA microarray data from van't Veer et $a l^{90}$ which included $18 B R C A 1$ and two $B R C A 2$ carcinomas, observed that $80 \%$ of BRCA1 carcinomas had a basal-type gene expression profile. Subsequently, Foulkes et $a^{91}$ and Palacios et $a 9^{92}$ found a high prevalence of tumors with a basal phenotype among BRCA1-mutation carriers. For example, Palacios et $a l^{92}$ reported that CK5/6 was expressed in $50 \%$ of BRCA1 tumors, but in fewer than $10 \%$ of BRCA2 tumors and sporadic control cases. In addition, this phenotype is characterized by estrogen receptor- and HER2-negativity and the expression of specific cell-cycle markers, such as overexpression of cyclin $\mathrm{E}$ and downregulation of 
p27 $7^{73}$ (Figure 2). Furthermore, a high proportion $(60 \%)$ of BRCA1 carcinomas are known to overexpress epidermal growth factor receptor (EGFR), which is considered to be another basal phenotype marker. ${ }^{93}$

\section{Histopathology and molecular features of familial non-BRCA1/2 tumors}

Very little is known about the genetic basis of nonBRCA1/2 breast cancer. Genetic linkage analysis of families has been performed and several chromosomal regions potentially harboring breast cancer susceptibility genes have been identified, including 8p12-p22, 13q21, and 2q31-q33. However, these loci have either been shown not to be major predisposing loci, or their status remains to be confirmed, thereby emphasizing genetic heterogeneity and population-specific effects among nonBRCA1/2 families. Non-BRCA1/2 hereditary carcinomas represent $67 \%$ of familial breast cancers when families with only female breast cancer and four or five affected members are considered. ${ }^{8}$ In the Spanish population, considering families with at least three cases of female breast cancer and one of the affected women being $<50$ years, $75 \%$ of cases were not attributable to BRCA1/2 mutation. ${ }^{94}$

There are three studies that have defined the histological characteristics of these neoplasias. ${ }^{34,36,95}$ In the three studies, invasive ductal carcinoma was the most frequent histological type: $77 \%$ of the cases according to Lakhani et al, ${ }^{95} 78 \%$ in the series of Palacios et $a l^{34}$ and $67 \%$ in the study of Eerola et al. ${ }^{36}$ In two of them, ${ }^{34,95}$ an excess of lobular carcinomas was found in familial non-BRCA1/2 (15\%) compared with BRCA1 (3\%), BRCA2 (9\%), and sporadic cases $(10 \%)$. The difference was only significant with respect to BRCA1 tumors. ${ }^{95}$

E-cadherin inactivation by gene mutation is characteristic of sporadic lobular carcinomas. In addition, germline mutations of the E-cadherin gene (CDH1) have been described in families with earlyonset diffuse gastric cancer, some of which are associated with lobular breast carcinomas. ${ }^{96}$ Considering these observations, it is reasonable to speculate that some familial lobular breast cancers that cannot be attributed to BRCA1 or BRCA2 mutations could instead be attributed to germline mutations in CDH1. However, germline $C D H 1$ mutation analysis in several non-BRCA1/2 lobular breast carcinomas has not revealed any genetic alterations. ${ }^{69,97}$

With respect to tumor grade, breast cancers from familial non-BRCA1/2 patients were of lesser histological grade than $B R C A 1 / 2$-associated tumors. Thus, grade 1 tumors accounted for $27-50 \%$ of the total. In addition, non-BRCA1/2 tumors showed more tubule formation, a lower mitotic index, and less pleomorphism than BRCA1/2-associated carcinomas. $^{34,95}$
In the immunohistochemical ${ }^{34,36,95}$ and $\mathrm{FISH}^{34}$ analysis in familial non-BRCA1/2, these tumors were more frequently estrogen receptor- (73-75\%), progesterone receptor- (54-67\%), and BCL2-positive (55\%), but p53-negative (78-96\%); these figures clearly differed from $B R C A 1$ tumors, but no significant differences were found with respect to $B R C A 2$ carcinomas. A low incidence of HER2 expression and amplification ( $4 \%$ ) was found in non-BRCA1/2 carcinomas. ${ }^{34}$ In addition, some chromosome aberrations involving chromosome 17 were observed: five cases $(23 \%)$ showed polysomy, and two cases $(9.5 \%)$ were monosomic. Finally, $c-M Y C$ amplification was observed in two (12\%) non-BRCA1/BRCA2 tumors.

Kainu et $a l^{98}$ investigated the molecular alterations of non-BRCA1/2 tumors by using chromosomal comparative genomic hybridization and linkage analysis to study 61 breast tumors from 37 breast cancer families with no identified $B R C A 1$ or $B R C A 2$ mutations. Losses in non-BRCA1/2 tumors were most often seen on chromosome arms 13q (56\%), $6 \mathrm{q}$ (41\%), 11q (30\%), 9p (26\%), and Xq (26\%). Gains in non-BRCA1/2 tumors were clustered in regions that are also typical of unselected breast cancers, such as 1q $(46 \%), 17 q(39 \%), 8 q(36 \%)$, and 16p (34\%), whereas losses were more evenly distributed throughout the genome. In non-BRCA1/2 cancers, the total of copy number alterations (CNAs) was $9.4 \pm 5$, which was not significantly different from the sporadic set $(7.7 \pm 5.1)$. However, the non$B R C A 1 / 2$-associated tumors did have fewer CNAs than BRCA1-associated $(12.2 \pm 5.3)$ and BRCA2associated $(12.5 \pm 4.9)$ tumors. Branching and phylogenetic tree models predicted that loss of $13 q$ was one of the earliest genetic events in these non$B R C A 1 / 2$ hereditary cancers.

Hedenfalk et al ${ }^{99}$ used the complementary strategy of global gene-expression profiling and comparative genomic hybridization to subclassify non-BRCA1/2 tumors. The authors found two groups (A and B) of tumors based on the expression of 60 genes. Interestingly, many of the genes with increased expression in group A relative to group B were ribosomal, possibly indicating different capacities for protein biosynthesis for these groups. The two groups were not significantly different from each other with respect to clinical and histopathological factors. However, although not statistically significant, individuals in group A tended to have a later age at onset of disease and the tumors had a low percentage of cells in S-phase. This may indicate a less aggressive appearance of these tumors. Moreover, groups $\mathrm{A}$ and $\mathrm{B}$ manifested significantly different expression of the CYP1A1 gene, which encodes a phase I cytochrome P450 enzyme known to play a central role in the metabolism of a wide range of compounds, including steroids. The authors analyzed the genomic content of eight individual tumors by comparative genomic hybridization and identified 262 DNA clones that displayed 
significant differences. In particular, a large number of clones were located on $8 q 24$, and this region was significantly amplified in group B compared with group A.

\section{Implications for Genetic Testing}

The results presented above on the morphological and immunohistochemical characteristics of hereditary breast cancer illustrate major differences between genotypes. The most important were those between tumors in BRCA1 carriers and all other categories. These histopathological features, in conjunction with clinical data, can be used to predict $B R C A 1$ status and, to a lesser extent, BRCA2 and non-BRCA1/2 status and this could have implications for the process of mutation screening.

In families with a high incidence of breast and ovarian cancer (six or more cases) there is a high probability of finding a BRCA1 or BRCA2 germline mutation. In the absence of other clinical features suggesting the alteration of a specific gene, such as prostate cancer and BRCA2 mutations, histopathological features can be used to indicate which gene should be screened first. Grade 3, estrogen receptorand progesterone receptor-negative infiltrating ductal carcinomas are more common among BRCA1 patients, specially if they show medullary features. These cases should be also tested for CK5/6 and EGFR expression, since the positive staining of any of these makers further increase the probability of being a BRCA1 mutation carrier. Estrogen receptorand/or progesterone receptor-positive tumors without evidence of basal differentiation should first be tested for BRCA2 mutations.

In cases with less familial aggregation, the same rules should be taken into account, however the frequency of non-BRCA1/2 tumors increases. For example, it would be very unusual to find a $B R C A 1$ or BRCA2 mutation in a case with a grade 1 tumor with high tubule formation, that is estrogen receptor- and progesterone receptor-positive and p53negative and has a very low proliferation index. In such circumstances, it would probably be sufficient to study only the more common mutations in each population in order to reduce the possibility of missing BRCA1 cases without the typical phenotype.

In the absence of a family history of breast and ovarian cancer, we should suspect a BRCA1-hereditary carcinoma in women diagnosed before age 35 years that have a grade 3 , estrogen receptor-negative infiltrating ductal carcinoma, since the incidence of BRCA1 germline mutations in these cases is around $27 \% .{ }^{25}$ These tumors should be analyzed for the expression of CK5/6, HER2 and EGFR, since the identification of a basal phenotype probably increase the likelihood of being a BRCA1-mutation carrier, although this hypothesis remains to be tested. In our opinion, in such situations, the pathologist should raise the possibility of a BRCA1 mutation in the report. In addition, since a panel with these four antibodies (estrogen receptor, HER2, CK5/6, EGFR) can accurately identify the basal-like phenotype, ${ }^{100}$ we recommend testing for these four markers in all grade 3 sporadic tumors, including results in the diagnostic report because of their possible prognostic and therapeutic implications.

Several techniques, such as random fine-needle aspiration, ductal lavage, and nipple aspirate fluid, are being used to detect atypical breast epithelial cells to improve risk stratification for women who already have an elevated risk of developing breast carcinoma. However, taking into account the special characteristics of patients with BRCA1 or BRCA2 mutations, there is a need to identify new ways of providing individual women with additional information regarding their risk of breast carcinoma. Detecting molecular changes, such as BRCA1/2 $\mathrm{LOH}$, in nonatypical cells obtained by these methods may help to earlier identify those women who are at an even higher risk of developing breast carcinoma. In this way, Osorio et $a l^{47}$ studied LOH at the BRCA1/2 locus in tumors from women with deleterious mutations, with variants of unknown significance most of which were suspected of being nondeleterious mutations, and with several common polymorphisms. They found that more than $90 \%$ of tumors with deleterious mutations had $\mathrm{LOH}$ of the wild-type allele, while this was the case in fewer than $5 \%$ of tumors with variants of unknown significance and common polymorphisms. The authors concluded that $\mathrm{LOH}$ analysis of the tumor is a test of high sensitivity (around 90\%) and specificity (around 95\%) for determining whether a germline variant in the $B R C A$ genes in a case of familial breast cancer is either a deleterious mutation or a common polymorphism. Isaacs et $a l^{101}$ took this molecular approach in BRCA1 patients, but extracting free DNA from the ductal fluid instead of using epithelial cells. The authors studied the presence of LOH in the BRCA1 and FHIT genes, and mitochondrial DNA mutations in the D310 marker. They evaluated 26 ductal lavage and six nipple aspirate fluid samples from 14 women of known BRCA1 status, who had no clinical evidence of breast tumors: nine mutation carriers and five noncarriers. LOH studies of the BRCA1 locus were possible in 19 out of 26 ductal lavage samples, and at the FHIT locus in 16 out of 26 samples. In four out of nine mutation carriers $\mathrm{LOH}$ at the BRCA1 allele was found, and in two of these $\mathrm{LOH}$ at the FHIT allele was also found. In one of the mutation carriers with BRCA1 LOH, invasive breast cancer was subsequently detected, and the tumor showed the same $\mathrm{LOH}$ as the ductal lavage.

\section{Therapeutic Implications}

From a therapeutic point of view, adjuvant hormone therapy is not indicated in most BRCA1 tumors, 
since they are estrogen receptor- and progesterone receptor-negative, but can be used in most $B R C A 2$ and non-BRCA1/2 carcinomas. Antihormonal therapy, including tamoxifen, raloxifene, and other selective estrogen receptor modulators, ovarian ablation (oophorectomy, radiation, or chemical ablation), and aromatase inhibitors, is being used to prevent both primary breast cancer and contralateral cancer after a primary tumor. Of these treatments, only oophorectomy and tamoxifen have been studied in BRCA1- and BRCA2-mutation carriers. Three studies have reported that prophylactic oophorectomy reduced the risk of developing breast cancer in BRCA1-mutation carriers by $50 \% .^{102}$ However, the benefit of tamoxifen remains controversial. The protective effect of tamoxifen against breast cancer has been demonstrated in women with moderate risk factors, but the data specific for carriers of BRCA1 mutations remain unclear. A study involving 13388 women whose risk factors included an age of more than 60 years, a history of preneoplastic breast lesions, or a positive family history of breast cancer, found a $50 \%$ reduction in the risk of breast cancer that could be attributed to tamoxifen therapy, although this effect was limited to estrogen receptor-positive tumors. Of 288 women with breast cancer who could be evaluated, only $6.6 \%$ had a BRCA mutation. A trend towards a protective effect of tamoxifen was found among carriers of BRCA2 mutations, but not among carriers of BRCA1 mutations. Breast cancers arising in carriers of BRCA1 mutations are commonly estrogen receptor-negative, unlike tumors associated with BRCA2 mutations, suggesting that the effect of tamoxifen might be selective for distinct genotypes. ${ }^{103}$

By contrast with these results, and supporting studies of prophylactic oophorectomy that suggested that hormonal manipulation might be effective in carriers of both BRCA1 and BRCA2 mutations, Narods et $a l^{104}$ reported that tamoxifen use reduced the risk of contralateral breast cancer by $50 \%$ in women with pathogenic mutations in the BRCA1 or BRCA2 gene. However, these results have been questioned based on different methodological issues. $^{105}$ Foulkes et $a l^{106}$ also suggested that adjuvant tamoxifen might be an effective treatment for BRCA1-related breast cancer, irrespective of the estrogen receptor status of the tumor. The authors hypothesized that tamoxifen might induce cell death via oxidative stress in estrogen receptornegative cancer cells, and that this effect might be more prominent in BRCA1-null cells, which have profoundly defective DNA repair. Thus, tumors that lack both estrogen receptor and BRCA1 may respond differently to tamoxifen than those that lack only estrogen receptor.

Although these findings suggest that hormonal interventions should help to lower the risk among women who carry mutations, this needs to be confirmed in prevention trials such as the ongoing study of tamoxifen and raloxifene, and these trials should include young women who carry mutations in BRCA1 or BRCA2.

Finally, given the low incidence of HER2 amplification and overexpression in most hereditary breast cancers, these tumors are not good candidates for treatment with herceptin. However, the high incidence of EGFR recently reported in BRCA1 tumors $^{93}$ offers the possibility that these women could be treated with specific compounds, such as tyrosine kinase inhibitors or anti-EGFR monoclonal antibodies.

\section{Acknowledgements}

This work was partially financed by projects from the Spanish Ministry of Health (FIS G03-179), the Spanish Ministry of Science and Technology (SAF01-075 and SAF03-02497). EH is recipient of research grant from the Fondo de Investigaciones Sanitarias.

\section{References}

1 Miki Y, Swensen J, Shattuck-Eidens D, et al. A strong candidate for the breast and ovarian cancer susceptibility gene BRCA1. Science 1994;266:66-71.

2 Wooster R, Bignell G, Lancaster J, et al. Identification of the breast cancer susceptibility gene BRCA2. Nature 1995;378:789-792.

3 Easton DF, Bishop DT, Ford D, et al. Genetic linkage analysis in familial breast and ovarian cancer: results from 214 families. The Breast Cancer Linkage Consortium. Am J Hum Genet 1993;52:678-701.

4 Stratton MR, Ford D, Neuhasen S, et al. Familial male breast cancer is not linked to the BRCA1 locus on chromosome 17q. Nat Genet 1994;7:103-107.

5 Diez O, Osorio A, Duran M, et al. Analysis of BRCA1 and BRCA2 genes in Spanish breast/ovarian cancer patients: a high proportion of mutations unique to Spain and evidence of founder effects. Hum Mutat 2003;22:301-312.

6 Ford D, Easton DF, Peto J. Estimates of the gene frequency of BRCA 1 and its contribution to breast and ovarian cancer incidence. Am J Hum Genet 1995;57: 1457-1462.

7 Easton DF, Narod SA, Ford D, et al. The genetic epidemiology of BRCA1. Breast Cancer Linkage Consortium. Lancet 1994;344:761.

8 Ford D, Easton DF, Stratton M, et al. Genetic heterogeneity and penetrance analysis of the BRCA1 and BRCA2 genes in breast cancer families. The Breast Cancer Linkage Consortium. Am J Hum Genet 1998;62:676-689.

9 Marroni F, Aretini P, D’Andrea E, et al. Penetrances of breast and ovarian cancer in a large series of families tested for BRCA1/2 mutations. Eur J Hum Genet 2004; 12:899-906.

10 Easton DF, Ford D, Bishop DT. Breast and ovarian cancer incidence in BRCA1-mutation carriers. Breast Cancer Linkage Consortium. Am J Hum Genet 1995; 56:265-271.

11 Warner E, Foulkes W, Goodwin P, et al. Prevalence and penetrance of BRCA1 and BRCA2 gene mutations 
in unselected Ashkenazi Jewish women with breast cancer. J Natl Cancer Inst 1999;91:1241-1247.

12 Scott CL, Jenkins MA, Southey MC, et al. Average agespecific cumulative risk of breast cancer according to type and site of germline mutations in BRCA1 and BRCA2 estimated from multiple-case breast cancer families attending Australian family cancer clinics. Hum Genet 2003;112:542-551.

13 King MC, Marks JH, Mandell JB. Breast and ovarian cancer risks due to inherited mutations in BRCA1 and BRCA2. Science 2003;302:643-646.

14 Struewing JP, Abeliovich D, Peretz T, et al. The carrier frequency of the BRCA1 185delAG mutation is approximately 1 percent in Ashkenazi Jewish individuals. Nat Genet 1995;11:198-200.

15 Thorlacius S, Sigurdsson S, Bjarnadottir H, et al. Study of a single BRCA2 mutation with high carrier frequency in a small population. Am J Hum Genet 1997;60:1079-1084.

16 Cipollini G, Tommasi S, Paradiso A, et al. Genetic alterations in hereditary breast cancer. Ann Oncol 2004;15(Suppl 1):I7-I13.

17 Venkitaraman AR. Cancer susceptibility and the functions of BRCA1 and BRCA2. Cell 2002;108:171-182.

18 Bertwistle D, Ashworth A. Functions of the BRCA1 and BRCA2 genes. Curr Opin Genet Dev 1998;8:14-20.

19 Pellegrini L, Venkitaraman A. Emerging functions of BRCA2 in DNA recombination. Trends Biochem Sci 2004;29:310-316.

20 Zhang J, Willers H, Feng Z, et al. Chk2 phosphorylation of BRCA1 regulates DNA double-strand break repair. Mol Cell Biol 2004;24:708-718.

21 Powell SN, Kachnic LA. Roles of BRCA1 and BRCA2 in homologous recombination, DNA replication fidelity and the cellular response to ionizing radiation. Oncogene 2003;22:5784-5791.

22 Moynahan ME, Pierce AJ, Jasin M. BRCA2 is required for homology-directed repair of chromosomal breaks. Mol Cell 2001;7:263-272.

23 Tutt A, Bertwistle D, Valentine J, et al. Mutation in Brca2 stimulates error-prone homology-directed repair of DNA double-strand breaks occurring between repeated sequences. EMBO J 2001;20:4704-4716.

24 Snouwaert JN, Gowen LC, Latour AM, et al. BRCA1 deficient embryonic stem cells display a decreased homologous recombination frequency and an increased frequency of non-homologous recombination that is corrected by expression of a brca1 transgene. Oncogene 1999;18:7900-7907.

25 Lakhani SR, Van De Vijver MJ, Jacquemier J, et al. The pathology of familial breast cancer: predictive value of immunohistochemical markers estrogen receptor, progesterone receptor, HER-2, and p53 in patients with mutations in BRCA1 and BRCA2. J Clin Oncol 2002;20:2310-2318.

26 Lakhani SR, Jacquemier J, Sloane JP, et al. Multifactorial analysis of differences between sporadic breast cancers and cancers involving BRCA1 and BRCA2 mutations. J Natl Cancer Inst 1998;90: 1138-1145.

27 Lakhani SR, Easton DF, Stratton MR, et al. Pathology of familial breast cancer: differences between breast cancers in carriers of BRCA1 or BRCA 2 mutations and sporadic cases. Breast Cancer Linkage Consortium. Lancet 1997;349:1505-1510.

28 Armes JE, Egan AJ, Southey MC, et al. The histologic phenotypes of breast carcinoma occurring before age 40 years in women with and without BRCA1 or BRCA2 germline mutations: a population-based study. Cancer 1998;83:2335-2345.

29 Lakhani SR. The pathology of familial breast cancer: Morphological aspects. Breast Cancer Res 1999;1: 31-35.

30 Chappuis PO, Nethercot V, Foulkes WD. Clinicopathological characteristics of BRCA1- and BRCA2related breast cancer. Semin Surg Oncol 2000;18: 287-295.

31 Agnarsson BA, Jonasson JG, Bjornsdottir IB, et al. Inherited BRCA2 mutation associated with high grade breast cancer. Breast Cancer Res Treat 1998;47: 121-127.

32 Marcus JN, Watson P, Page DL, et al. BRCA2 hereditary breast cancer pathophenotype. Breast Cancer Res Treat 1997;44:275-277.

33 Marcus JN, Watson P, Page DL, et al. Hereditary breast cancer: pathobiology, prognosis, and BRCA1 and BRCA2 gene linkage. Cancer 1996;77:697-709.

34 Palacios J, Honrado E, Osorio A, et al. Immunohistochemical characteristics defined by tissue microarray of hereditary breast cancer not attributable to BRCA1 or BRCA2 mutations: differences from breast carcinomas arising in BRCA1 and BRCA2 mutation carriers. Clin Cancer Res 2003;9: 3606-3614.

35 Lynch BJ, Holden JA, Buys SS, et al. Pathobiologic characteristics of hereditary breast cancer. Hum Pathol 1998;29:1140-1144.

36 Eerola H, Heikkila P, Tamminen A, et al. Histopathological features of breast tumours in BRCA1, BRCA2, and in mutation negative breast cancer families. Breast Cancer Res 2005;7:R93-R100.

37 Foulkes WD, Metcalfe K, Sun P, et al. Estrogen receptor status in BRCA1- and BRCA2-related breast cancer: the influence of age, grade, and histological type. Clin Cancer Res 2004;10:2029-2034.

38 Armes JE, Trute L, White D, et al. Distinct molecular pathogeneses of early-onset breast cancers in BRCA1 and BRCA2 mutation carriers: a population-based study. Cancer Res 1999;59:2011-2017.

39 Robson ME, Chappuis PO, Satagopan J, et al. A combined analysis of outcome following breast cancer: differences in survival based on BRCA1/ BRCA2 mutation status and administration of adjuvant treatment. Breast Cancer Res 2004;6:R8-R17.

40 Osin P, Gusterson BA, Philp E, et al. Predicted antioestrogen resistance in BRCA-associated familial breast cancers. Eur J Cancer 1998;34:1683-1686.

41 Osin PP, Lakhani SR. The pathology of familial breast cancer: immunohistochemistry and molecular analysis. Breast Cancer Res 1999;1:36-40.

42 Hoogerbrugge N, Bult P, de Widt-Levert LM, et al. High prevalence of premalignant lesions in prophylactically removed breasts from women at hereditary risk for breast cancer. J Clin Oncol 2003;21:41-45.

43 Kauff ND, Brogi E, Scheuer L, et al. Epithelial lesions in prophylactic mastectomy specimens from women with BRCA mutations. Cancer 2003;97:1601-1608.

44 Adem C, Reynolds C, Soderberg CL, et al. Pathologic characteristics of breast parenchyma in patients with hereditary breast carcinoma, including BRCA1 and BRCA2 mutation carriers. Cancer 2003;97:1-11.

45 Futreal PA, Liu Q, Shattuck-Eidens D, et al. BRCA1 mutations in primary breast and ovarian carcinomas. Science 1994;266:120-122. 
46 Staff S, Isola JJ, Johannsson O, et al. Frequent somatic loss of BRCA1 in breast tumours from BRCA2 germline mutation carriers and vice versa. Br J Cancer 2001;85:1201-1205.

47 Osorio A, de la Hoya M, Rodriguez-Lopez R, et al. Loss of heterozygosity analysis at the BRCA loci in tumor samples from patients with familial breast cancer. Int J Cancer 2002;99:305-309.

48 Cavalli LR, Singh B, Isaacs C, et al. Loss of heterozygosity in normal breast epithelial tissue and benign breast lesions in BRCA1/2 carriers with breast cancer. Cancer Genet Cytogenet 2004;149:38-43.

49 Esteller M, Fraga MF, Guo M, et al. DNA methylation patterns in hereditary human cancers mimic sporadic tumorigenesis. Hum Mol Genet 2001;10:3001-3007.

50 Silva JM, Gonzalez R, Provencio M, et al. Loss of heterozygosity in BRCA1 and BRCA2 markers and high-grade malignancy in breast cancer. Breast Cancer Res Treat 1999;53:9-17.

51 Kelsell DP, Spurr NK, Barnes DM, et al. Combined loss of BRCA1/BRCA2 in grade 3 breast carcinomas. Lancet 1996;347:1554-1555.

52 Tirkkonen M, Johannsson O, Agnarsson BA, et al. Distinct somatic genetic changes associated with tumor progression in carriers of BRCA1 and BRCA2 germ-line mutations. Cancer Res 1997;57:1222-1227.

53 Wessels LF, van Welsem T, Hart AA, et al. Molecular classification of breast carcinomas by comparative genomic hybridization: a specific somatic genetic profile for BRCA1 tumors. Cancer Res 2002;62:7110-7117.

54 Alvarez S, Diaz-Uriarte R, Osorio A, et al. A predictor based on the somatic genomic changes of the BRCA1/ BRCA2 breast cancer tumors identifies the nonBRCA1/BRCA2 tumors with BRCA1 promoter hypermethylation. Clin Cancer Res 2005;11:1146-1153.

55 Crook T, Brooks LA, Crossland S, et al. p53 mutation with frequent novel codons but not a mutator phenotype in BRCA1- and BRCA2-associated breast tumours. Oncogene 1998;17:1681-1689.

56 Phillips KA, Nichol K, Ozcelik H, et al. Frequency of p53 mutations in breast carcinomas from Ashkenazi Jewish carriers of BRCA1 mutations. J Natl Cancer Inst 1999;91:469-473.

57 Goffin JR, Chappuis PO, Begin LR, et al. Impact of germline BRCA1 mutations and overexpression of p53 on prognosis and response to treatment following breast carcinoma: 10-year follow up data. Cancer 2003;97:527-536.

58 Greenblatt MS, Chappuis PO, Bond JP, et al. TP53 mutations in breast cancer associated with BRCA1 or BRCA2 germ-line mutations: distinctive spectrum and structural distribution. Cancer Res 2001;61: 4092-4097.

59 Gasco M, Yulug IG, Crook T. TP53 mutations in familial breast cancer: functional aspects. Hum Mutat 2003;21:301-306.

60 Johannsson OT, Idvall I, Anderson C, et al. Tumour biological features of BRCA1-induced breast and ovarian cancer. Eur J Cancer 1997;33:362-371.

61 Grushko TA, Blackwood MA, Schumm PL, et al. Molecular-cytogenetic analysis of HER-2/neu gene in BRCA1-associated breast cancers. Cancer Res 2002; 62:1481-1488.

62 Adem C, Soderberg CL, Hafner K, et al. ERBB2, TBX2, RPS6KB1, and MYC alterations in breast tissues of BRCA1 and BRCA2 mutation carriers. Genes Chromosomes Cancer 2004;41:1-11.
63 Grushko TA, Dignam JJ, Das S, et al. MYC is amplified in BRCA1-associated breast cancers. Clin Cancer Res 2004;10:499-507.

64 Kauraniemi P, Hedenfalk I, Persson K, et al. MYB oncogene amplification in hereditary BRCA1 breast cancer. Cancer Res 2000;60:5323-5328.

65 Cortesi L, Turchetti D, Bertoni C, et al. Comparison between genotype and phenotype identifies a highrisk population carrying BRCA1 mutations. Genes Chromosomes Cancer 2000;27:130-135.

66 Sherr CJ, McCormick F. The RB and p53 pathways in cancer. Cancer Cell 2002;2:103-112.

67 Vaziri SA, Krumroy LM, Elson P, et al. Breast tumor immunophenotype of BRCA1-mutation carriers is influenced by age at diagnosis. Clin Cancer Res 2001;7:1937-1945.

68 Loden M, Stighall M, Nielsen NH, et al. The cyclin D1 high and cyclin E high subgroups of breast cancer: separate pathways in tumorogenesis based on pattern of genetic aberrations and inactivation of the $\mathrm{pRb}$ node. Oncogene 2002;21:4680-4690.

69 Palacios J, Honrado E, Osorio A, et al. Phenotypic characterization of BRCA1 and BRCA2 tumors based in a tissue microarray study with 37 immunohistochemical markers. Breast Cancer Res Treat 2005; 90:5-14.

70 Hedenfalk I, Duggan D, Chen Y, et al. Gene-expression profiles in hereditary breast cancer. N Engl J Med 2001;344:539-548.

71 Vaziri SA, Tubbs RR, Darlington G, et al. Absence of CCND1 gene amplification in breast tumours of BRCA1 mutation carriers. Mol Pathol 2001;54:259-263.

72 Chappuis PO, Kapusta L, Begin LR, et al. Germline BRCA1/2 mutations and p27(Kip1) protein levels independently predict outcome after breast cancer. J Clin Oncol 2000;18:4045-4052.

73 Foulkes WD, Brunet JS, Stefansson IM, et al. The prognostic implication of the basal-like (cyclin E high/p27low/p53+/glomeruloid-microvascular-proliferation+) phenotype of BRCA1-related breast cancer. Cancer Res 2004;64:830-835.

74 Schraml P, Bucher C, Bissig H, et al. Cyclin E overexpression and amplification in human tumours. J Pathol 2003;200:375-382.

75 Landberg G. Multiparameter analyses of cell cycle regulatory proteins in human breast cancer: a key to definition of separate pathways in tumorigenesis. Adv Cancer Res 2002;84:35-56.

76 Krajewski S, Krajewska M, Turner BC, et al. Prognostic significance of apoptosis regulators in breast cancer. Endocr Relat Cancer 1999;6:29-40.

77 McEachern KA, Archey WB, Douville K, et al. BRCA1 splice variants exhibit overlapping and distinct transcriptional transactivation activities. J Cell Biochem 2003;89:120-132.

78 Hadjiloucas I, Gilmore AP, Bundred NJ, et al. Assessment of apoptosis in human breast tissue using an antibody against the active form of caspase 3 : relation to tumour histopathological characteristics. Br J Cancer 2001;85:1522-1526.

79 Wetzels RH, Kuijpers HJ, Lane EB, et al. Basal cellspecific and hyperproliferation-related keratins in human breast cancer. Am J Pathol 1991;138:751-763.

80 Palacios J, Benito N, Pizarro A, et al. Anomalous expression of P-cadherin in breast carcinoma. Correlation with E-cadherin expression and pathological features. Am J Pathol 1995;146:605-612. 
81 Tsuda H, Takarabe T, Hasegawa F, et al. Large, central acellular zones indicating myoepithelial tumor differentiation in high-grade invasive ductal carcinomas as markers of predisposition to lung and brain metastases. Am J Surg Pathol 2000;24:197-202.

82 van de Rijn M, Perou CM, Tibshirani R, et al. Expression of cytokeratins 17 and 5 identifies a group of breast carcinomas with poor clinical outcome. Am J Pathol 2002;161:1991-1996.

83 Korsching E, Packeisen J, Agelopoulos K, et al. Cytogenetic alterations and cytokeratin expression patterns in breast cancer: integrating a new model of breast differentiation into cytogenetic pathways of breast carcinogenesis. Lab Invest 2002;82: 1525-1533.

84 Callagy G, Cattaneo E, Daigo Y, et al. Molecular classification of breast carcinomas using tissue microarrays. Diagn Mol Pathol 2003;12:27-34.

85 Perou CM, Sorlie T, Eisen MB, et al. Molecular portraits of human breast tumours. Nature 2000;406: 747-752.

86 Signoretti S, Di Marcotullio L, Richardson A, et al. Oncogenic role of the ubiquitin ligase subunit Skp2 in human breast cancer. J Clin Invest 2002;110:633-641.

87 Peralta Soler A, Knudsen KA, Salazar H, et al. Pcadherin expression in breast carcinoma indicates poor survival. Cancer 1999;86:1263-1272.

88 Gamallo C, Moreno-Bueno G, Sarrio D, et al. The prognostic significance of P-cadherin in infiltrating ductal breast carcinoma. Mod Pathol 2001;14: 650-654.

89 Sorlie T, Tibshirani R, Parker J, et al. Repeated observation of breast tumor subtypes in independent gene expression data sets. Proc Natl Acad Sci USA 2003;100:8418-8423.

90 van 't Veer LJ, Dai H, van de Vijver MJ, et al. Gene expression profiling predicts clinical outcome of breast cancer. Nature 2002;415:530-536.

91 Foulkes WD, Stefansson IM, Chappuis PO, et al. Germline BRCA1 mutations and a basal epithelial phenotype in breast cancer. J Natl Cancer Inst 2003; 95:1482-1485.

92 Palacios J, Honrado E, Osorio A, et al. Re: germline BRCA1 mutations and a basal epithelial phenotype in breast cancer. J Natl Cancer Inst 2004;96:712-714.

93 van der Groep P, Bouter A, van der Zanden R, et al. Re: germline BRCA1 mutations and a basal epithelial phenotype in breast cancer. J Natl Cancer Inst 2004;96:712-713 author reply 714 .

94 Osorio A, Barroso A, Martinez B, et al. Molecular analysis of the BRCA1 and BRCA2 genes in 32 breast and/or ovarian cancer Spanish families. Br J Cancer 2000;82:1266-1270.

95 Lakhani SR, Gusterson BA, Jacquemier J, et al. The pathology of familial breast cancer: histological features of cancers in families not attributable to mutations in BRCA1 or BRCA2. Clin Cancer Res 2000; 6:782-789.

96 Pharoah PD, Guilford P, Caldas C. Incidence of gastric cancer and breast cancer in CDH1 (E-cadherin) mutation carriers from hereditary diffuse gastric cancer families. Gastroenterology 2001;121:1348-1353.

97 Salahshor S, Haixin L, Huo H, et al. Low frequency of E-cadherin alterations in familial breast cancer. Breast Cancer Res 2001;3:199-207.

98 Kainu T, Juo SH, Desper R, et al. Somatic deletions in hereditary breast cancers implicate $13 q 21$ as a putative novel breast cancer susceptibility locus. Proc Natl Acad Sci USA 2000;97:9603-9608.

99 Hedenfalk I, Ringner M, Ben-Dor A, et al. Molecular classification of familial non-BRCA1/BRCA2 breast cancer. Proc Natl Acad Sci USA 2003;100:2532-2537.

100 Nielsen TO, Hsu FD, Jensen K, et al. Immunohistochemical and clinical characterization of the basal-like subtype of invasive breast carcinoma. Clin Cancer Res 2004;10:5367-5374.

101 Isaacs C, Cavalli LR, Cohen Y, et al. Detection of LOH and mitochondrial DNA alterations in ductal lavage and nipple aspirate fluids from hngh-risk patients. Breast Cancer Res Treat 2004;84:99-105.

102 Rebbeck TR, Levin AM, Eisen A, et al. Breast cancer risk after bilateral prophylactic oophorectomy in BRCA1 mutation carriers. J Natl Cancer Inst 1999;91: 1475-1479.

103 King MC, Wieand S, Hale K, et al. Tamoxifen and breast cancer incidence among women with inherited mutations in BRCA1 and BRCA2: National Surgical Adjuvant Breast and Bowel Project (NSABP-P1) Breast Cancer Prevention Trial. Jama 2001;286: 2251-2256.

104 Narod SA, Brunet JS, Ghadirian P, et al. Tamoxifen and risk of contralateral breast cancer in BRCA1 and BRCA2 mutation carriers: a case-control study. Hereditary Breast Cancer Clinical Study Group. Lancet 2000;356:1876-1881.

105 Bryson A, Massey J. Tamoxifen's effect in women with breast cancer. Lancet 2001;357:1291 author reply 1291-1292.

106 Foulkes WD, Goffin J, Brunet JS, et al. Tamoxifen may be an effective adjuvant treatment for BRCA1-related breast cancer irrespective of estrogen receptor status. J Natl Cancer Inst 2002;94:1504-1506. 